\title{
Encountering the vitrine
}

\section{Distance and proximity effects in museum vitrines}

\author{
Ane PilegaArd
}

\begin{abstract}
This article analyses spatial dynamics in museum vitrine design through the lens of art theorist Rosalind E. Krauss' grid concept. Due to the regularity of shelves, compartments and lattice framework, vitrines are characterized by a grid structure which, following Krauss' conceptualization, has a double function: it frames a space within, and at the same time, extends outwards beyond its own framework. While museum literature often tells us that vitrines have a distancing effect, this article argues that because of their dual ability to frame and create focus, together with their grids' extension into the space in which the museum visitor moves, vitrines can also generate a sense of bodily proximity. This argument draws on Walter Benjamin's distinction between optical, distanced focus and haptic, proximate distraction. However, rather than maintaining an opposition between distance and proximity, the article emphasizes the oscillation between simultaneous distance and proximity effects in museum vitrine design.
\end{abstract}

Keywords: Museum vitrine, exhibition design, grid, Rosalind E. Krauss, Walter Benjamin, anatomical collection display.

Vitrines, along with other types of exhibition cases, are fundamental components of many museum exhibitions. When of older date, they tend to manifest themselves as antiquated, yet impressive, testimonies of a museum's long history. While in museums where the modernist ideal of transparency has had its influence, vitrines are often stripped down to be as invisible as possible (Carroll 2013). The vitrine is connected to the visual hegemony of museums (Brenna 2014), which has often been criticized for inhibiting touch and other types of multisensory engagement with objects on display (Classen \& Howes 2006, Levent \& Pascal-Leone 2014). Furthermore, vitrines can be seen to epitomize a rather outdated, purely visual technique of museum display (HooperGreenhill 1992). These negative connotations easily lead to an understanding of the vitrine as a necessary evil, with the primary functions of keeping the objects from being touched, protecting them from dust, and regulating climate. However, this article argues that the vitrine can also be considered in more positive terms. It can focus visitor attention and frame exhibition content, and might, in fact, contribute to creating a sense of proximity to objects on display. If we limit ourselves to considering vitrines as an unfortunate, although necessary, exhibition element, we miss the chance to take 
Ane PilegaArd

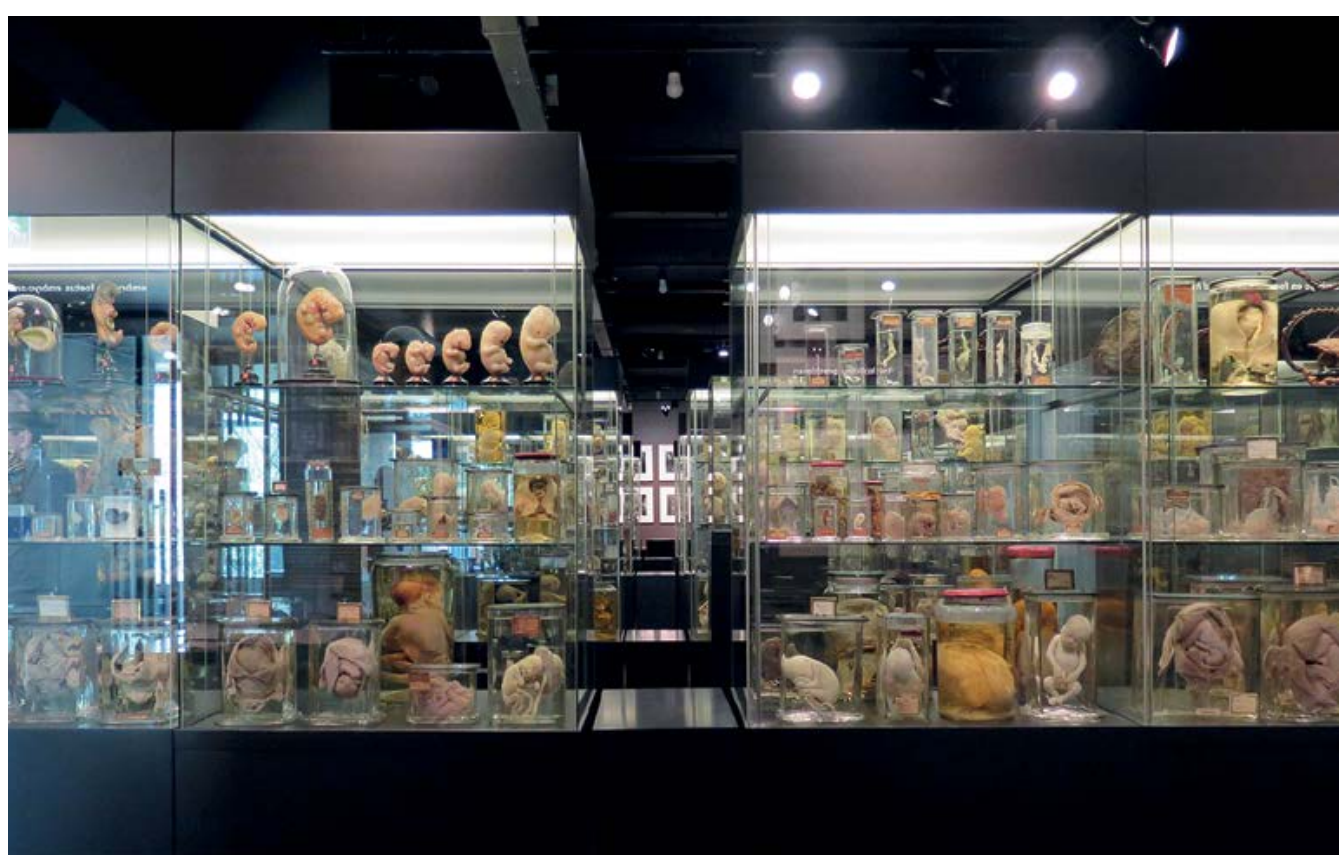

Fig. 1. Museum Vrolik: Grid structure in vitrines. Photo: Ane Pilegaard, 2015.

advantage of the more productive potential of vitrine spatiality and its effects on museum visitor perception.

The purpose of this article is to unpack and investigate the spatial complexities of museum vitrines, and to find ways to talk about them. For the purpose of developing a model for this vitrine analysis, I adopt Rosalind E. Krauss' seminal concept of the grid, which is used as a conceptual tool to unlock and grasp the spatial complexities in vitrine design. The grid is characterized by its dual ability to direct and concentrate itself "within-the-frame", while, at the same time, extending outwards "beyondthe-frame" (Krauss 1986:21). This double function is, as we shall see, very much present in museum vitrines. Furthermore, Krauss' grid concept addresses the important aspect of the spatial relation between the viewing subject and the grid object, which is highly relevant to museum display. In her analytical approach, the perception of the grid is considered to be affected by specific distances and viewpoints of the subject, and this understanding of spatial subject-object relations and how they are negotiated by vitrines is used for grasping the dynamics of visitor perception in museums. ${ }^{1}$

Under the heading of Krauss' grid concept, I argue that vitrines create oscillations between distance and proximity effects, inwards and outwards dynamics, and that these might address various perception modes in the museum visitor. The latter will be discussed by drawing on Walter Benjamin's thoughts on optical contemplation versus haptic distraction, which he puts forth in his seminal Work of Art essay. Here Benjamin connects focused optical contemplation to the 'auratic' object, 
which he defines by its "unique manifestation of a remoteness, however close it may be" (Benjamin 2008:9). The aura concept is sometimes used to describe the way museum vitrines can enhance the sense of authenticity and preciousness of objects on display (Henning 2006, Endt-Jones 2013), and can thus be considered a positive outcome of museum vitrines' distance effects. Adding further nuance to its application, museum scholar Gottfried Korff has used Benjamin's aura concept to talk about "the oscillation between near and far that is particular to things in the museum. Things are near to the observer spatially (graspable) but mentally and cognitively distant and alien" (Korff 1999:268). This idea of a continuous oscillation between distance and proximity effects will also be discussed in this article. However, whereas Korff (and Benjamin before him) attaches the sense of distance to conceptual reception, and proximity to actual perception, thus presenting a curious mix of abstract and concrete experience modes, I will consider both distance and proximity as concrete spatial effects within a physical, graspable domain. This approach challenges the binary opposition

Fig. 2. Museum Vrolik: Nineteenth century vitrine placed as centrepiece amidst contemporary vitrine design. Photo: Ane Pilegaard, 2015.

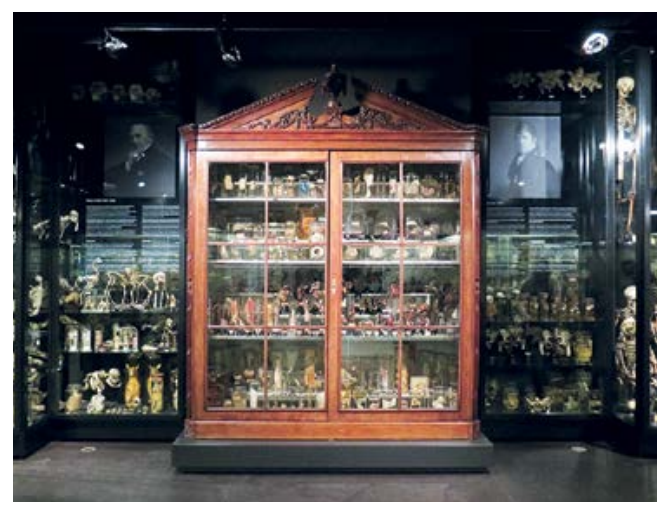

between distance and proximity and the contrast implied in Benjamin's writings. Thus, I will argue that spatial oscillations in vitrine design are the product of distance-proximity and focus-distraction alliances.

\section{First ENCOUNTERS}

For the purpose of developing and demonstrating an analytical model for capturing spatial dynamics in museum vitrines, I analyze a series of vitrines at three medical museums: Museum Vrolik (Amsterdam), Hunterian Museum (London), and Musée Testut Latarjet (Lyon). The vitrines are all designed and used for the display of human and animal specimens, such as body parts preserved in glass jars to show anatomical/pathological details. The body-to-body encounter between the museum visitor body and the specimens (mostly human) that these vitrines produce, is likely to have a strong emotional impact on the museum visitor. ${ }^{2}$ Thus, in terms of distance and proximity effects, one might argue that in the case of human specimens, some sense of distance is necessary in order for a non-medical public to cope with what they encounter. However, this article focuses solely on how the vitrines affect the viewer in terms of aesthetic composition and, thus, does not go into ethical or anthropologicalsociological questions of encountering the dead, medicalized body, nor does it unfold the psycho-sensory aspects of such an encounter. Anatomical collection vitrines make good case studies for comparative aesthetic analyses since the objects they contain are relatively similar and they are, at least the examples analyzed here, curated in a rather modest and homogenous way. In other words, when comparing vitrines in the three museums, the 
Ane PilegaArd

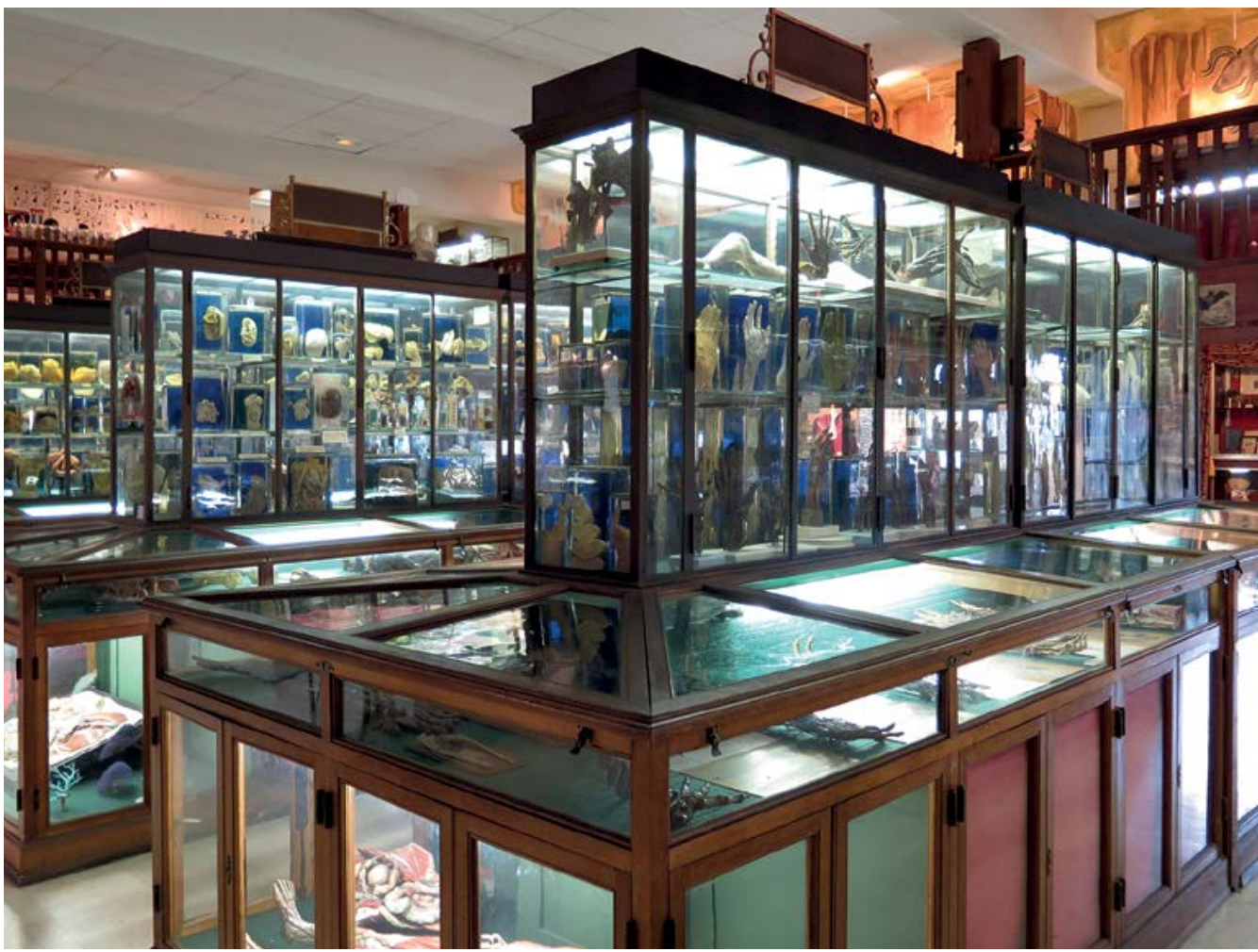

Fig. 3. Musée Testut Latarjet: Dense composition of nineteenth century vitrines. After my visit in 2015 the Testut Latarjet collection has been moved to new domiciles and will be part of Lyon's future Musée des Sciences Médicales et de la Santé (Museum of Medical Sciences and Health). Photo: Ane Pilegaard, 2015.

objects they display look fairly similar, thereby making it possible to detect differences and effects that rely on the vitrine designs as such, rather than in the curated objects.

Moreover, the grid structure might be said to manifest itself especially clearly in anatomical collection displays due to the rigid regularity of the often rectangular glass jars that conveniently fall in line with the overall vitrine grid. As such, the repetitive aesthetics of the grid connects well to museum display taxonomies and, especially, to the scientific categorizations within natural historical and medical collections, where similar specimens are organized in groups and series in order to be compared (Forgan 1994, Psarra 2009, Tybjerg 2016). Unlike many other museum types, medical museums have, to a large extent, maintained these display strategies for their anatomical collections, which, of course, relates to the fact, that the specimen objects were originally produced - by technicians and scientists - for the purpose of comparative display and analysis. As such, the vitrine in anatomy displays shares the logic of the preservation jars containing the specimens. 
Like the glass jars that sit on the vitrine shelves, the vitrine stabilizes objects in space and time and enables us to look at the objects inside (Putnam 2009:15). Thus, due to their prominent grid structures, anatomical collection vitrines present a particularly pertinent case for the analysis of grid composition in vitrine design. However, the inward and outward functions of the grid can be found in many other types of museum vitrines as well.

When comparing vitrines in the three medical museums, the dichotomy between old and new is immediately apparent. Whereas the old vitrines (fig. 2 and 3) appear almost as museum objects in themselves, evoking cultural-historical associations with the past, the newer ones (fig. 1 and 4) connect to a more modern understanding of the cool rationality in natural sciences. However, vitrine design, and how it affects our perception of the objects they contain, is not just a matter of old versus new, wood versus steel, and the culturally coded connotations that these material characteristics suggest. The ways in which the vitrines are spatially structured are just as important. This is the case both internally - the way objects are placed and organized within the vitrine and externally - the vitrines' scale and layout within the surrounding space. Therefore, when examining how old vitrines can appear as museum objects in themselves, it is not simply due to their strong historical material presence, but also has to do with the way the vitrines are placed within the exhibition space. This is exemplified at Museum Vrolik, where one vitrine is positioned as a centerpiece between other, less distinct, vitrines (fig. 2), while others are placed by themselves, detached in space as secluded objects (fig. 6 and 7). From this perspective, vitrines can be considered in two distinct ways: either they can be seen as pieces of bounded furniture that close in on themselves

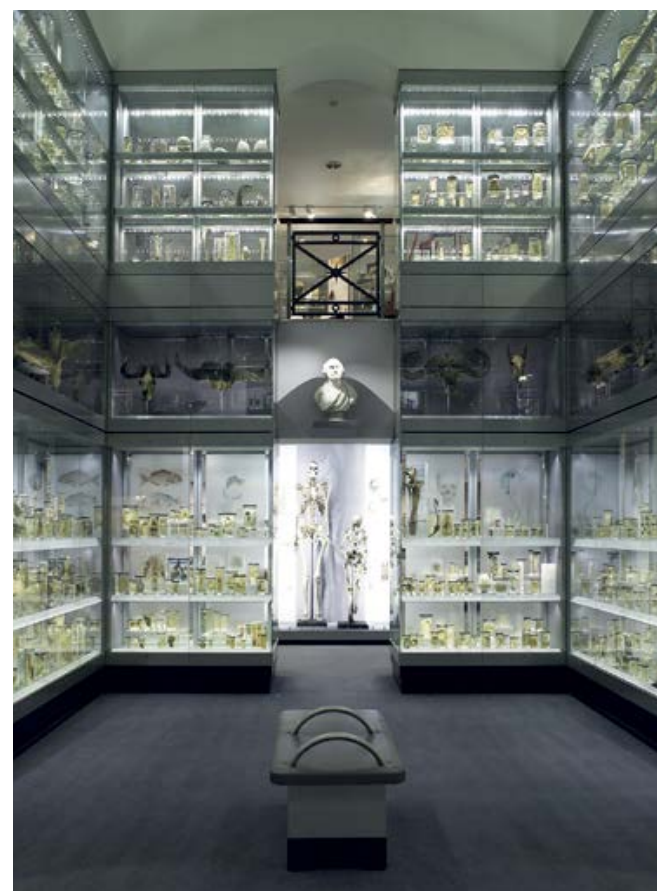

Fig. 4. Hunterian Museum: The illuminated, steel structure displaying human and animal specimens has been named the Crystal Gallery. (C) The Hunterian Museum at the Royal College of Surgeons.

like sculptural entities, or, alternatively, by considering the extending structures of the modern vitrine systems at Museum Vrolik and Hunterian Museum, they can be approached in terms of (modern) architectural design. Thus, when looking at vitrines as designed aesthetic objects, vitrines can be seen to resemble both sculpture (enclosed space in front of the museum visitor) and architecture (space around, in which the museum visitor moves). Additionally, because of the flatness of the vitrine surface, and the way it delineates a certain framed space, vitrines can also resemble the picture plane in painting. Of course, these are very simplified understandings of sculpture, 
architecture and painting and, certainly, in modern/contemporary art these categories continuously break their own boundaries. The simplification may, however, be productive when architecture, sculpture and painting are used as analytical categories, representing differing spatial structures. However, as we shall see, the argument of this article does, in fact, support the project of dissolving the boundaries between them.

\section{OSCILLATING DISTANCES}

The three categories of sculpture, architecture, and painting (the latter understood with an emphasis on the framed picture plane rather than pictorial qualities or painting technique) are used in the following analyses as tools for concretizing spatial structures in vitrine design. However, the purpose is not to simply categorize different vitrines as either sculptural, architectural, or as paintings. Indeed, the different categories tend to merge and transform into each other, influenced by the changing positioning of the viewer's body. In order to capture these transformations, the concept of the grid is used because it can negotiate between and across the three categories. In other words, whereas sculpture, architecture and painting are concepts that separate differing spatial structures, the grid is what binds these structures together. Thus, if one were to create a mental image of the article's analytical framework, it would unfold as a three-dimensional matrix directing itself inwards, where it captures and organizes the vitrines' internal spatial structures, while also extending outwards, where it grasps the viewing body and the external spatial setting. Thus, my analytical framework is quite similar to the vitrine grid itself, and situates the analyses in terms of viewer position and movement, thereby taking both objective and subjective aspects into account.

In relation to the grid concept, Krauss develops an analytical approach to Minimalist art and architecture (Agnes Martin's paintings and Mies van der Rohe's architecture, to be more specific) that mends the rift between objectivist and subjectivist approaches in art theory. This approach, which she calls "objectivist opticality", can be taken as an analytical method of oscillating between different viewing distances. Building on Alois Riegl's art theory, especially his thoughts on relief sculpture, Krauss writes: "Since the figure/ground fluctuation varies with the stance of the viewer, one might argue that the object, now fully dependent upon its perceiver, has become entirely subjectivized." By this "objectivist opticality", or "phenomenology of seeing", as she also calls it, Krauss proposes "an attempt to discover - at the level of pure abstraction - the objective conditions [...] for the purely subjective phenomenon of vision itself." This drive towards an objective understanding of the art work, she states, is of course "impossibly outmoded, formalist, determinist, empty". However, as she also argues, its typical alternative has limitations as well: "the rush to move beyond the circumscribed aesthetic sphere to the horstexte, the context, the legitimating 'real' text, often produces superficial readings" (Krauss 1996:116-119). Krauss' notion of how oscillation between different distances/ viewpoints extends the structural system of the aesthetic object so as to include the viewing subject is highly useful for analyzing museum vitrines. It makes it possible to maintain a focus on the vitrines as designed objects, while also taking a phenomenological perspective on the museum visitor's situatedness into account.

Building on this approach, the following 
analyses progress in three steps, zooming in through three different viewing positions: distant-sight, middle-sight and near-sight. These viewing positions might, at first, be seen to correspond to different types of aesthetic objects. For instance, distant-sight might be seen to best capture the larger scale of architecture, while near-sight suits the perception of smaller sculptures or paintings. However, as we shall see, when taking viewing positions into account, rather than building the analyses on pure objectivism, the individual vitrines tend to oscillate between aesthetic categories.

\section{Distant-sight: Approaching the VITRINE}

In the first analysis, the viewing subject is placed in distant-sight, although rather than adopting a static point of view, this distantsight is performed by the viewer's moving body as the vitrines are approached. Since the analysis builds on my own encounter with the vitrines, I myself constitute this viewing subject, though, of course, the notion of a more general museum visitor subject guides the analytical perspective.

Depending on the overall spatial layout and size of the room in which the exhibition takes place, some exhibitions allow for more distant views than others. For instance, the Crystal Gallery at Hunterian (fig. 4), with its two story vitrine room, is spacious enough for the museum visitor to keep a certain distance from the objects on display. At Testut Latarjet, on the other hand, you enter a much more cramped room, in which the vitrines are placed no more than one meter apart, allowing only narrow passages between them (fig. 3). From the idea of architectural vs. sculptural spatiality it seems obvious to ascribe architectural qualities to the large vitrine system at the Hunterian, which functions somewhat like a room-within-a-room. In contrast, the vitrines at Testut Latarjet present themselves more like sculptural object entities dispersed in the exhibition room - at least when the vitrines are viewed separately. But the vitrines at Testut Latarjet are not viewed separately. Due to the comprised layout of the room, the distanced position that such a view would entail is simply not possible. Or, at least not before you walk up the stairs to the balcony above. From this view the vitrines on the ground floor can be overlooked and comprehended as separate sculptural entities (fig. 5).

Similarly, at the Hunterian, the Crystal Gallery also shifts between architectural and sculptural modes as you move between different floor levels. However, here the best overview of the vitrine system - comprehended as an object - is gained on the lower floor, inside the cubical vitrine room, by looking up and around. Despite the vitrine system's function as an architectural enclosure, its readily recognizable cubical shape presents itself as a sculptural entity. When viewed from outside this cubical enclosure, however, the vitrine system appears more like typical wall vitrines, since the ceiling/floor that separates the museum's two stories prevents the full overview of the vitrine cube. Clearly, the position and movement of the viewing subject is crucial for how the vitrine designs in the two museums appear. However, the design of the vitrines themselves, their shapes and lines, is also highly significant. This is where the formal principles of Krauss' grid concept become useful.

The grid, Krauss states, both has "centrifugal" and "centripetal" functions. Centrifugal in that it "extends, in all directions, to infinity" and presents itself "as a mere fragment, a tiny 
Ane PilegaArd

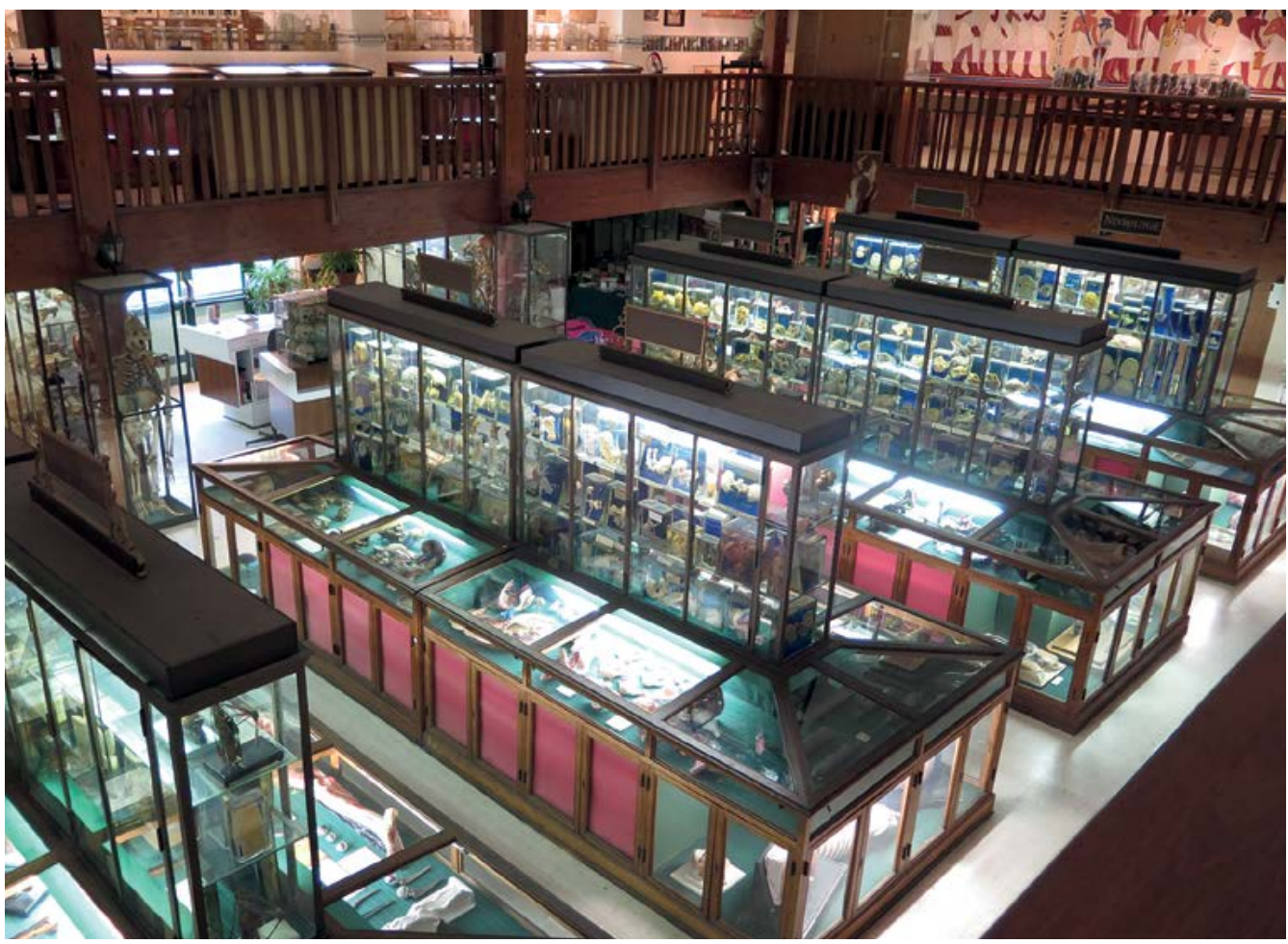

Fig. 5. Musée Testut Latarjet: View from the balcony. Photo: Ane Pilegaard, 2015.

piece arbitrarily cropped from an infinitely larger fabric". At the same time the grid is centripetal, taking on a "within-the-frame" attitude: "The grid is an introjection of the boundaries of the world into the interior of the work; it is a mapping of the space inside the frame onto itself" (Krauss 1986:18-21). It is exactly this double function that makes the grid concept truly interesting in terms of museum vitrine design. Vitrines both have the ability to seclude themselves from their spatial context, and the ability to extend into and integrate with the space in which the museum visitor moves. This can explain why the same vitrines appear to oscillate back and forth between sculptural and architectural modes.
Now, lets see how these oscillations between centripetal and centrifugal functions occur when coming closer, while also assuming a more static viewing position.

\section{Middle-sight: Arrested Attention}

When viewing Museum Vrolik, movement is frequently arrested. This is partly due to the objects themselves; for instance, a row of dissected hands or a pair of conjoined twins that catches the eye and makes the viewer stop to look. However, the old wooden vitrines have a similar affect. They also arrest attention, both because of their dissimilarity to other more modern vitrines, and due to their placement 


\section{ENCOUNTERING THE VITRINE}

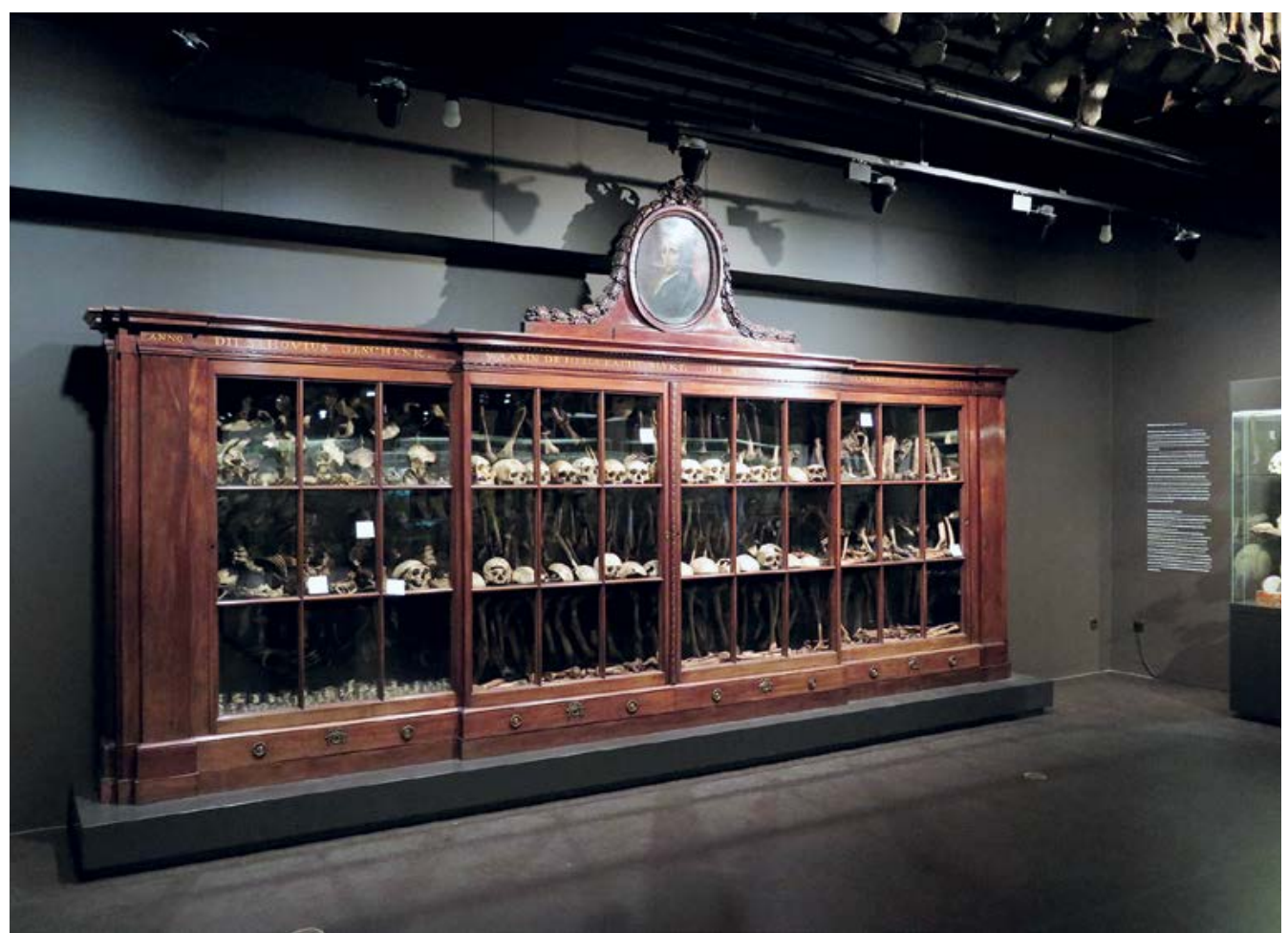

Fig. 6. Museum Vrolik: Original collection vitrine from eighteenth century. Photo: Ane Pilegaard, 2015.

Fig. 7. Museum Vrolik: Reconstruction of original collection vitrine. Photo: Ane Pilegaard, 2015.

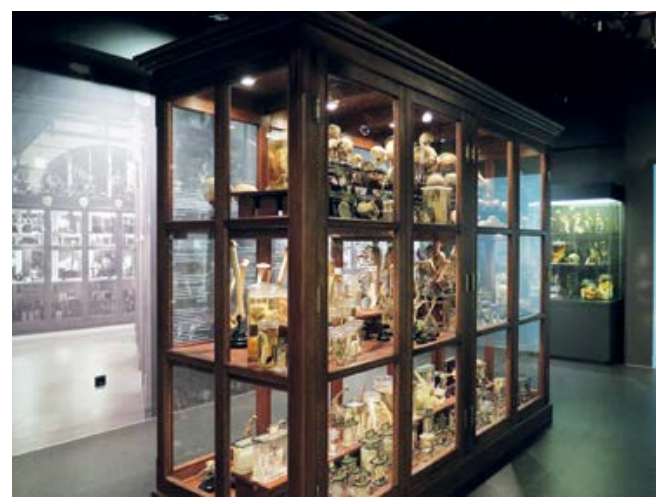

as either secluded, detached objects (fig. 6 and 7) or symmetrical centerpiece (fig. 2). The way these vitrines demarcate themselves in space - aided by their heavy wooden framework make them present themselves as solid, static shapes, which encourages the viewer to stop and take a position in front of them. This is especially the case with the vitrines in fig. 2 and 6, which appear almost like framed paintings on a wall. It might exactly be because of this flat and framed appearance that the viewer stops to look - contemplating the vitrine as a whole - as one would do when looking at a painting. 
14 Krauss connects the concept of the grid to that of the window, which opens up another dimension, namely the space - or the illusion of a space - beyond the gridded surface. However, still stressing the grid's double function, she writes: "the window is experienced as simultaneously transparent and opaque. [...] the window is this matrix of ambi- or multivalence, and the bars of the windows - the grid - are what help us to see, to focus on, this matrix" (Krauss 1986:16-17). Again, it must be mentioned that Krauss is talking about painting and that the window, which she finds in symbolist art, of course does not completely correspond to the glass panes of museum vitrines. However, the conceptual pairing of the grid and the window can, indeed, inform the analysis of vitrine design. Like windows, the vitrine has the ability to direct focus and frame a space that is markedly different than the space in which the viewer is positioned.

This connection between Krauss' gridwindow in painting and the grid of the vitrine has also been pointed to by art historian Elyse Speaks, who discusses the use of vitrines in contemporary art, more specifically, in relation to works by Damien Hirst (whose artworks relate to the anatomical displays discussed here, as they also display (animal) body specimens). Speaks writes: "the vitrine operates in contemporary art as both surface and lens, [...] providing structure through which the gaze can pass, but also a frontier at which movement is arrested" (Speaks 2013:232). This dual function of allowing the gaze through, but arresting bodily movement is, indeed, a basic vitrine attribute. However, the balance between these two functions is far from static. The way vitrines manage their functions as opaque surface and/or transparent lens depends on the specific vitrine design and how it relates to its spatial context, just as it is affected by the (changing) viewing position of the museum visitor.

\section{Balancing surface and lens}

When comparing the vitrines in fig. 6 and 7 , it is clear how these three parameters of material design, spatial context, and viewing position affect the opacity/transparency of the two vitrines. Both vitrines are old-fashioned in style. The one in fig. 6 dates back to the eighteenth century, while the vitrine in fig. 7 is a reconstruction of an old vitrine design from the nineteenth century. However, the two vitrines also differ in numerous ways. First of all, the vitrine in fig. 6 is placed against the wall, while the vitrine in fig. 7 is freestanding, thereby allowing the museum visitor to walk around it. Secondly, there is no internal lighting in the wall vitrine, meaning that the objects are lit from the outside, whereas, in the freestanding vitrine, internal lighting has been installed, which makes the vitrine appear as an illuminated entity in the otherwise dim exhibition space. Thirdly, the way in which objects have been arranged inside the vitrines differs. In the wall vitrine, the objects are placed in rigid rows on the shallow shelves, close to the glass front and in an externally oriented way, which is especially evident in the case of the outwards facing sculls on the upper rows. By contrast, in the freestanding vitrine, the objects are distributed on the broad shelves (part of them on an elevated podium along the central axis) in a manner that sets the objects back from the glass fronts of the vitrine. Some are grouped in terms of object type (for instance bones in one group and specimens in glass jars in another), thereby creating internally oriented spatial orders within the vitrine. Thus, comparing the grid structures of the two vitrines, one might say that the rows of objects 
in the wall vitrine complement and underline the surface grid, whereas, in the freestanding vitrine, the objects fill up the internal space of the vitrine without complying, or at least not complying as rigidly, with the external lattice grid.

When considering Krauss' idea of the window-grid as having both transparent and opaque qualities, it might be tempting to simply state that the freestanding vitrine is transparent since its internal lighting and the open space around makes it see-through and, conversely, consider the wall vitrine opaque because of its rather dark and obscure internal space. However, Krauss' point is exactly that the window is both transparent and opaque, and the same can be said about the vitrines analyzed here. The freestanding vitrine, although allowing the gaze to pass through, also closes in on itself, thereby making it difficult for the gaze to find a point of entry. This quality of opacity is due to the fact that the vitrine's gridded surface and, thereby, its ability to direct and extend its grid out towards the viewer, is somehow outmaneuvered by the luminance of the internal lighting and the inwards orientation of the objects. Thus, the vitrine presents itself as an independent sculptural object, around which the viewing body circles. Even though this activity of circling around might be said to manifest the kind of centrifugal power that Krauss attributes the grid, this is not exactly the case, since the centrifugal dynamics derive from within the vitrine, rather than from the grid structure of the vitrine surface. Conversely, even though the wall vitrine appears rather opaque when it first arrests the viewer's attention and, thereby, presents itself as a somewhat impenetrable surface, it is partly the sense of something lurking inside that makes the viewer focus and move to an even closer position. Here it is the grid structure that is lit up and in focus, at least before the viewer hones in on the objects inside. Functioning as a lens, the grid structures not only the vitrine surface but also the objects within, as well as the spatial positioning of the museum visitor in relation to these aspects.

Again, it becomes evident how vitrines can have the ability to concurrently frame their own space and invite the viewer's gaze and body into that space, thereby creating a viewing situation that oscillates between two poles of perception: distanced overview and proximate inspection. However, as we have just seen, the way in which the different vitrines succeed in balancing these two poles vary. Whereas the wall vitrine uses its transparent and opaque qualities in a manner in which they reinforce each other productively, the opaque and transparent functions of the freestanding vitrine seem to, instead, be somewhat contradictory. The contrast between the illuminated, inwards oriented objects inside the vitrine and the darkened space outside the vitrine (resulting, also, in a darkened grid surface), is simply too great for the vitrine's grid to negotiate. This is something that, of course, cannot be attributed entirely to the vitrine's design and spatial surroundings, but also has to do with the viewer's subjective movement patterns. Once again, the vitrines oscillate between opacity and transparency and between centripetal and centrifugal functions, depending on both objective design features, spatial surroundings, and subjective viewing positions.

Let us now move to the last stage of the analytical "zoom in", where the viewing body gets so close to the vitrine surface that it is no longer able to apprehend its delimiting frame. In this proximate position, body movement is arrested, but the eye's gaze continues to move to a greater depth. 


\section{NEAR-SIGHT: EXTENDING THE GRID}

When stepping in close, one becomes aware that there is also space behind the vitrine. For instance, the modern vitrine system at Vrolik, which fills up the large central space of the exhibition room, enables views across space from one vitrine element to the other (fig. 1). On the level of exhibition content, this can be seen to accentuate the way anatomical collections constitute a scientifically structured body of human material distributed out through space. Additionally, when looking at exhibition form, these visual axes can also be seen to rupture the bounded shape of the singular vitrine body, which brings us back to the grid concept and its ability to extend centrifugally beyond its own frame. In this section the analysis stresses the third dimension of the grid's extension in depth.

This feature of extension in depth is also apparent at Testut Latarjet (fig. 8). Despite the many reflections in the glass (which is old and, therefore, slightly hazy) and the blue back panels in the specimen jars, it is still possible to see through to the vitrine behind and, in some instances, even further, to the third and fourth vitrine in the row. The viewer sees, then, grid upon grid, or if focusing on the vitrines' spatial interconnection, a continuous grid in three dimensions. This three-dimensional grid is composed of both opaque surfaces and transparent windows that open up in the gaps and interstices between the specimens. The grid, perhaps, owes its three-dimensional appearance exactly to the interplay between opacity and transparency, since the opaque surfaces are precisely what frames the transparent windows between them. (This effect is less apparent at Vrolik, where vitrines and glass jars are generally more transparent.) When looking in and through these vitrines it becomes a matter of tuning the eye so that different objects - in the front, in the middle, or in the back - come in and out of focus, thereby blurring the singular surface grid of the vitrine.

Under consideration here is a three-dimensional grid that is simultaneously blurry and sharp, transparent and opaque, and it raises the possibility - indeed, the necessity - of thinking about distance-proximity oscillations in exhibition design in a manner that goes beyond individual vitrine design. When decreasing the body's distance to one vitrine, a new depth reveals itself through and behind that vitrine. In that sense, the vitrine grid deviates from Krauss' understanding of the grid in modern art, which is mainly tied to the two-dimensional surface of painting. Krauss notes about the grid, that it "displays perfectly the conditions of what could be called the visual - the simultaneity of vision's grasp of its field dissolving the spatial (tactile) separation of figure against ground into the continuous immediacy of a purely optical spread" (1986:118). However, unlike a painting of Piet Mondrian, whom Krauss uses to exemplify this "optical spread", the vitrines at Testut Latarjet do not present us with a flat spread in which figure and ground are superimposed on each other. On the contrary, they draw vision into depth, into their complex spatial grids, which also anticipates an extension in time. For while standing in front of one vitrine, the idea of continuing the walk and encountering the other vitrines behind and around it is implicit. At Vrolik the modern vitrine system presents us with a labyrinthine structure waiting to be explored, whereas the readily comprehensible row of vitrines at Testut Latarjet makes it easy to anticipate a further stroll along the narrow passages. 


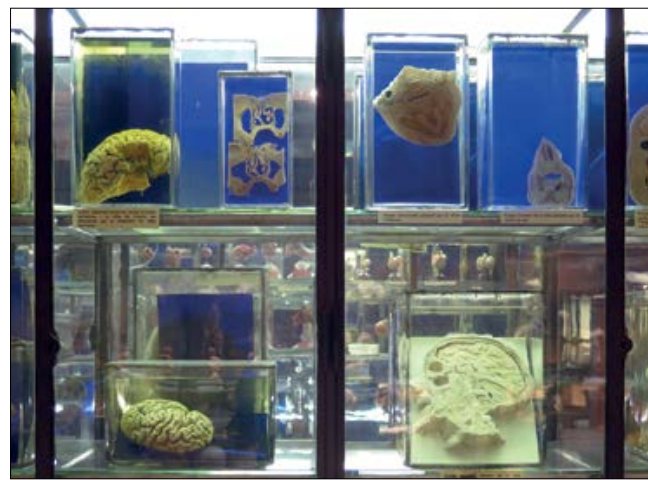

Fig. 8. Musée Testut Latarjet: Close-up view showing how visual axes continue through and behind the vitrine. Photo: Ane Pilegaard, 2015.

\section{Touching the grid}

At Testut Latarjet this bodily involvement is further enhanced by the vitrines' invitation to touch. Due to their horizontal side slopes and solid wooden construction, it is possible to lean over with the upper part of the body and/ or grab the vitrine edges with the hands. The vitrines do not merely engage the eye, but also allow, or even encourage, touching with the hands. Thus, unlike the vertical glass surfaces of the vitrines at Vrolik and Hunterian, these vitrines allow for a different level of bodily engagement, which is also a function of simple matters of scale. Compared to the grandiose architectural scale of the Crystal Gallery at Hunterian, the dimensions of the vitrines at Testut Latarjet relates more readily to the human body. Also, the close-up tactile encounter at Testut Latarjet is supported by the fact that the vitrines are placed relatively close together, thereby hindering a distanced stroll. With just one tiny step forward and the curiousness of one's hands, the arrested optical attention of middle-sight is very easily turned into a tactile encounter within the range of near-sight. Following Krauss' thoughts on 'objectivist opticality" this vitrine design surely makes "the field of its viewer". Furthermore, it connects to another aspect of the "tactilization" that Krauss identifies in modern art, where the "logic of vision" becomes "infected by the tactile" (1986:118-119). This infection (which she frames positively), depends on the manner in which the grid coincides with its material support; a quality that is easily recognized in the vitrines at Testut Latarjet. Enhancing the obvious material support of their grid provided by their solid wooden construction (which is also a quality in the old vitrines at Vrolik), these vitrines literally turn the optical encounter with the grid into a tactile one.

This tactile encounter can be seen to exemplify an extreme case of the kind of haptic proximity that Walter Benjamin connects with architectural perception. Building on Riegl's ideas of near-sight (Nahsicht) and distant-sight (Fernsicht) (as did Krauss), but subverting the original scheme, in which Riegl traces an art historical development from haptic Nahsicht (in ancient Egyptian art) to optical Fernsicht (in late Roman art) (Riegl 1985:24-27), Benjamin connects the proximity of the tactile sensory mode (Nahsicht) to the distracted perception of the modern masses (Iversen 1993:16). Distraction, Benjamin states, is also constitutive for the kind of habitual use-perception that architecture addresses, and is thus formulated as a counterpoint to the optical contemplation that aura invites (2008:34-35).

This binary conceptualization of optical contemplation on the one hand, and haptic distraction on the other, presents a way of understanding distance and proximity effects in museum vitrines. As we have seen, vitrines have the ability to frame and direct focus in a way that enables a contemplative overview. At the same time, via the effect of spatial 
interconnectedness with other vitrines, as well as the possibility of touch, vitrines can also address a less optically dependent mode of perception, which could be understood in terms of haptic proximity. Yet, the analyses have also shown that this simple binary paring of focus with distance and distracted movement with proximity does not always hold. Focus does not cease when the vitrine is approached up close, but rather, through zooming and tuning in, it extends in depth. Likewise, the bodily-engaged viewer's distracted perception does not only occur within the proximity of touch, but is also an effect of a more distanced stroll through the spatial complex of vitrines. Thus, when Benjamin differentiates between architecture and painting by accentuating how architectural structures are experienced "without the distancing effect of the frame of the pictorial space" (1999:90), he omits the vitrine grid's ability to negotiate and bridge different aesthetic categories (architecture, sculpture, painting) and modes of perception (focus and distraction; distance and proximity). ${ }^{3}$ This discrepancy can, of course, be explained by the fact that Benjamin, in his historiographic approach to questions of aura, combines ideas of space and time, resulting in a mix of both concrete and abstract understandings of distance and proximity, whereas this article seeks to maintain a grasp of distance and proximity as matters of actual, situated spatiality. Furthermore, while Benjamin considers painting and architecture within their socio-cultural contexts, the present study turns them into detached "models", in order to make them applicable as analytic tools.

\section{DISSECTING THE VITRINE}

While the vitrine grid's oscillations between architecture, sculpture, and painting seems to break with Benjamin's binary differentiation, his thoughts on film technique can help us come to grips with the complex spatial effects of museum vitrines. Benjamin writes: "the camera intervenes with its different aids, its plunging and soaring, its stretching and condensing of the process, its close-ups and its distance shots" (2008:30). The technique he describes seems to capture the oscillating effects of the museum vitrine and how it can arrest attention, invite for casual strolls, draw the body close and direct the gaze. Furthermore, Benjamin uses surgical dissection (which resonates well with the anatomical content of the vitrines analyzed here) as a metaphor for film technique, as he notes how the cameraman "penetrates deep into the subject's tissue." This does not merely make possible a closer, clarifying look, but completely alters the matter at hand: "enlargement is not really concerned with simply clarifying what we glimpse 'anyway' but rather brings out wholly new structural formations in matter" $(2008: 25,29)$.

Jonathan Crary, in his thinking on modern vision, adds a further layer to this perspective, when suggesting that "long fixation sets the world in motion" by which "parts of the visual field begin vibrating and oscillating" (Crary 2001:300). Unlike common notions of visual perception that link fixed, immobile vision with the "conceptual mastery of phenomena" (similar to a traditional understanding of museum logic and the function of the vitrine, as well as to Benjamin's aura concept and the associated notion of optical contemplation), Crary argues that once the eye stops moving a more volatile, disintegrated vision takes place. On the contrary, he says, it is the mobile eye that preserves a pre-constructed understanding of the world, since the mobile eye "habitually, familiarly caresses objects, extracting only previously established relations 
from among them" (Crary 2001:299-300). On the one hand this proposition subverts Benjamin's implied association of static focus with distanced contemplation but, on the other hand, it connects to his thoughts about the zooming camera's ability to bring out "new structural formations in matter". This proposition might enhance our understanding of how material objects in museums are, or might be, perceived.

Thus, following Benjamin and Crary, museum perception can be seen to depend on the "camera technique" of the museum visitor's movements, gaze and touch, where the long fixation of the immobile focus can be used for its ability to destabilize matter and reveal otherwise unnoticed material details in the objects before us. ${ }^{4}$ For instance, this technique may operate by revealing the delicate texture of a heart specimen, or the bundle of tendons in a dissected foot, so that these objects become more than simply a heart or a foot on display. However, this idea of the camera eye also presents a risk of upholding the optical regime that museums are currently trying to leave behind, and might fail to capture the embodied and multisensory aspects of the museum encounter. In order to emphasize this embodied mode of perception, as well as continuing with Benjamin's surgery analogy, the vitrine can also be seen as a body under dissection and the museum visitor as the hand that does the cutting. Similar to the process of medical dissection that produced the specimens in the first place, the embodied gaze of the museum visitor - moving and pausing, stretching and condensing - can be understood as a gradual disclosure of what the vitrine bodies contain, continuously oscillating between the poles of distanced overview and proximate inspection. However, the shots and cuts that the vitrines invite, or even allows, of course varies, as these analyses have also shown. Thus, vitrine design (and its surrounding spatial design) marks the boundary conditions of the spatial set-up in which the camera's dissection knife is admitted to operate. In other words: the grid marks the cut, therebyhelping the museum visitor to frame and sharpen the lens. However, while camera work and dissection are most often guided by specific intention (for instance, zooming in on the main character in a film or cutting out a certain organ), the act of encountering museum vitrines, with its distracted, even unconscious, embodied responses and instances of blurred disintegration, will often be much less structured and willed.

\section{Conclusion}

When making exhibitions, we usually want visitors to focus and recognize the authenticity and importance of the things we show them. Vitrines can help us do that. On the other hand, they can also be criticized for addressing a distanced optical gaze and for not allowing a proximate bodily encounter with objects on display. This, however, is not all that vitrines can or cannot do. In this article, I have questioned simple notions of museum vitrines and, instead, developed and demonstrated an analytical model that unfolds their spatial complexities. The analyses have exemplified how simple distinctions between distance and proximity, focus and distraction, vision and touch, seem to dissolve in the complex spatial oscillations of vitrine grids, and that these conceptual dualities become productive allies rather than conflicting opposites. As an overarching analytical tool, Krauss' concept of the grid has captured diverse spatial dynamics and allowed passages and bridges between aesthetic categories (architecture, sculpture, painting), and between the opposing modes 
of perception that these can be seen to address. Thus, the grid concept has made it possible to talk about the intrinsic oscillations between different vitrine effects and modes of perception, rather than getting stuck with strict oppositions.

A notable insight from the analyses has been, that these oscillations seem to depend on how the vitrines manifest the double function of their grids - that is, the extent to which they manage to, simultaneously, direct themselves inwards and outwards. In some ways, it seems that the grids have manifested themselves more clearly in the old vitrines, partly because of the way their heavy wooden lattices make up a convincing material support for the grid structure. On the other hand, one might argue that new vitrine systems present their objects better: more clearly and in better light. However, from the perspective of this particular study, with its emphasis on spatial complexity and oscillations, a proposition could be that even lighting and unobtrusive steel constructions might, in fact, flatten the productive spatial impact of vitrines. When unobtrusive transparency is strived for - based on the idea that the disappearance of the glass plane will lessen the sense of distance to the objects on display - we risk missing out on the multiple effects and variations in perceptual modes that the spatial complexity of museum vitrines can generate. Moving through the analytical matrix of this article, concepts and terms for talking about this spatiality have been presented that might help us grasp and understand aspects of the otherwise rather elusive spatial effects of museum vitrines. This perspective is crucial if we want to use vitrines for their generative potential, rather than simply - and uncritically - employing them for their ability to establish a sense of aura, or, alternatively, criticizing them on grounds of their distancing effects.

\section{Notes}

1. When using Krauss' concept of the grid I, of course, have no intention of ascribing the article's purpose, nor the vitrine designs in question, to any modernist project in which the artists Krauss discusses might have been involved.

2. See Alberti (2007) and Brooks \& Rumsey (2007) for thoughts on the emotional response to anatomical collection displays.

3. For complementary discussions of Benjamin's writings in relation to vitrines and transparency, see Welchman (2013).

4. For a similar analogy between film technique and exhibitions, see Bal (2007).

5. I have proposed similar points about how display design can emphasize and support material object qualities in Pilegaard (2015).

\section{LITERATURE}

Alberti, Samuel J.M.M. 2007. “The museum affect.

Visiting collections of anatomy and natural history." In Aileen Fyfe \& Bernard Lightman (eds.). Science in the Marketplace. NineteenthCentury Sites and Experiences. Chicago:

University of Chicago Press, 371-403.

Bal, Mieke 2007. "Exhibition as film.” In Sharon Macdonald \& Paul Basu (eds.). Exhibition

Experiments. Malden: Blackwell Publishing, 71-93.

Benjamin, Walter 1999 [1933]. “The rigorous study of art." In Walter Benjamin. Selected Writings, Volume 2, 1927-1934. Cambridge, Mass.: The Belknap Press of Harvard University Press, 666-672.

Benjamin, Walter 2008 [1936]. The Work of Art in the Age of Mechanical Reproduction. London: Penguin Books.

Brenna, Brita 2014. "Nature and texts in glass cases.

The vitrine as a tool for textualizing nature." Nordic Journal of Science and Technology Studies, 2:1, 46-51. 
Brooks, Mary M. \& Claire Rumsey 2007. "Who knows the fate of ones bones? Rethinking the body on display: Object, art or human remains?" In Simon J. Knell, Suzanne Macleod \& Sheila Watson (eds.). Museum Revolutions. How Museums Change and are Changed. London: Routledge, 343-354.

Carroll, Khadija von Zinnenburg 2013. "Vitrinendenken. Vectors between subject and object." In G. Ulrich Grossmann \& Petra Krutisch (eds.). The Challenge of the Object, Congress of the International Committee of the History of Art. Nuremberg: Germanisches National Museum.

Classen, Constance \& David Howes 2006. "The museum as sensescape. Western sensibilities and indigenous artifacts." In Elizabeth Edwards, Chris Gosden \& Ruth B. Phillips (eds.). Sensible Objects. Colonialism, Museums and Material Culture. Oxford: Berg, 199-222.

Crary, Jonathan 2001. Suspensions of Perception. Attention, Spectacle and Modern Culture. Cambridge Mass.: The MIT Press.

Endt-Jones, Marion 2013. "Between Wunderkammer and Shop Window. Surrealist Naturalia Cabinets." In John C. Welchman (ed.). Sculpture and the Vitrine. Farnham: Ashgate, 95-120.

Forgan, Sophie 1994. "The architecture of display. Museums, universities and objects in nineteenthcentury Britain." History of Science, 32:2, 139-162.

Henning, Michelle 2006. Museums, Media and Cultural Theory. Maidenhead: Open University Press.

Hooper-Greenhill, Eilean 1992. Museums and the Shaping of Knowledge. London: Routledge.

Iversen, Margaret 1993. Alois Riegl. Art History and Theory. Cambridge Mass.: The MIT Press.

Korff, Gottfried 1999. "Reflections on the museum." Journal of Folklore Research, 36:2/3, 267-270.

Krauss, Rosalind E. 1986. The Originality of the AvantGarde and Other Modernist Myths. Cambridge Mass.: The MIT Press.
Krauss, Rosalind E. 1996. "The grid, the /cloud/, and the detail." In Detlef Mertins (ed.). Presence of Mies. New York: Princeton Architectural Press, 110-126.

Levent, Nina \& Alvaro Pascual-Leone (eds.) 2014. The Multisensory Museum. Cross-Disciplinary Perspectives on Touch, Sound, Smell, Memory, and Space. Lanham: Rowman \& Littlefield.

Pilegaard, Ane 2015. "Material proximity. Experimenting with material strategies in spatial exhibition design." Museum Worlds, 3, 69-85.

Psarra, Sophia 2009. Architecture and Narrative. The Formation of Space and Cultural Meaning. London: Routledge, 137-158.

Putnam, James 2009. Art and Artifact. The Museum as Medium. New York: Thames \& Hudson.

Riegl, Alois 1985 [1901]. Late Roman Art Industry. Rome: Giorgio Bretschneider.

Speaks, Elyse 2013. "The transparent signifier. Hirst, invisibility, and critique." In John C. Welchman (ed.). Sculpture and the Vitrine. Farnham: Ashgate, 231-249.

Tybjerg, Karin 2016. "The landscape of disease." In Karin Tybjerg (ed.). The Body Collected. The Raw Materials of Medical Science from Cadaver to DNA. Copenhagen: Medical Museion, 49. Welchman, John C. (ed.) 2013. Sculpture and the Vitrine. Farnham: Ashgate.

Ane Pilegaard, cand. design, Ph.D. candidate, Medical Museion, University of Copenhagen anepil@sund.ku.dk

\section{Medical Museion}

Fredericiagade 18

DK-1310 København K, Denmark www.museion.ku.dk 